\title{
KAJIAN HUNIAN FLEKSIBEL KOTA BAGI GENERASI MILLENNIAL
}

\author{
Andrew ${ }^{1}$ \\ ${ }^{1}$ Program Studi S1 Arsitektur, Fakultas Teknik, Universitas Tarumanagara, \\ alexandervincentiusandrew@gmail.com
}

\begin{abstract}
Abstrak
Generasi Millennial, generasi kelahiran tahun 1980 hingga tahun 2000 saat ini telah memasuki usia 20-49 tahun, mulai memenuhi kebutuhan pokok yaitu hunian. Perubahan sosial dan budaya generasi Millennial dalam kegiatan berhuni diperkirakan akan mengubah kebutuhan dan tipe hunian yang dibutuhkan bagi generasi millennial dari yang bersifat statis atau konvensional menuju ke arah yang lebih dinamis. Seperti diketahui generasi millennial saat ini membutuhkan ruang yang dapat berubah-ubah disesuaikan dnegan kebutuhan generasi millennial yang berubah-ubah keinginannya. Selain itu perbuahan jumlah penghuni hunian, serta harga hunian yang terus meningkat juga dapat mempengaruhi perubahan unit. Metode flexible architecture digunakna dalam perancangan ini dengan tujuan agar menciptakan ruang yang dapat fleksibel baik, fleksibel dalam modul unit ( dapat dilakukan fleksibel dalam ruang 1 modul unit dibantu dengan furnitur fleksibel ) maupun antara modul unit ( kemungkinan ekspansi modul unit menjadi 2 modul unit maupun 3 modul unit dengan perubahan pembatas antar unit, dll ) yang disesuaikan dengan katalog yang disediakan ( sesuai dengan kebutuhan dasar penghuni dan jumlah penghuni ), sehinggga kebutuhan ruang generasi millennial dapat terpenuhi melalui rancangan hunian fleksibel. Selain itu kepadatan penduduk yang semakin tinggi khususnya di daerah Jabodetabek serta harga hunian yang semakin meningkat menjadi tantangan tersendiri sehingga hunian fleksibel diharapkan dapat menjadi salah satu solusi untuk menampung generasi millennial serta mendukung daya beli generasi millennial.
\end{abstract}

Kata Kunci: Ekspansi; Fleksibel; Kebutuhan; Modul; Ruang

\begin{abstract}
Millenials, generation of people who was born between 1980 to 2000, age ranged from 20 to 39 years, are now preparing to fulfill one of the most important need in life: housing. Social and culture changes in millenials life style will affect millenials housing needs and type. It is known that millenials nowadays require a type of housing with high flexibility that can adjust well with their needs and wants rather than typical housing nowadays that is static and conventional. Changes in resident number and housing pricet can also affect unit changes This project will be using Flexible Architecture method which can provide flexible space to provide the millennials, whether in the flexibility of one modul unit (the flexibility of change in one modul unit by flexible furniture) or between modul units (the probability of expansion more than one modul unit by prefabricated flexible building envelope etc) that can be adjusted according to the catalog (according to residents basic needs and resident number). Hopefully flexible housing can fulfill millenials needs and budget when they search for housing to overcome the cause of over population and the ever-rising housing price, especially in Jabodetabek area.
\end{abstract}

Keywords: Expansion; Flexible; Modul; Needs; Space

\section{PENDAHULUAN}

Generasi millennial merupakan generasi yang lahir pada tahun 1980 - 2000, sudah memasuki usia 20 - 39 Tahun (IPSOS:2017) Generasi millennial saat ini merupakan generasi 
dengan populasi dominan di Indonesia saat ini. Tercatat kurang lebih 34,45\% jumlah penduduk di Indonesia merupakan generasi millennial. Hal ini membuat generasi millennial mulai memenuhi kebutuhan pokok yaitu kebutuhan akan hunian Seperti kita ketahui, generasi millennial dalam kegiatan berhuni saat ini memiliki berbagai perubahan baik dari segi sosial maupun budaya. Sebut saja saat ini generasi millennial dapat melakukan berbagai macam hal dalam 1 ruang, seperti dapat bekerja berisitrahat makan dan lain-lain. Hal ini berbeda dengan hunian masa lalu dimana semua ruangan sudah memiliki batasan dan fungsi yang jelas. Jumlah penghuni juga mengalami perubahan pada generasi millennial, seperti ada yang memilih hidup sendiri, berkeluarga namun menunda memilki keturunan, dan lain-lain. Ada juga yang lebih memilih untuk memiliki hunian ada juga yang ingin menyewa hunian. Belum lagi dilihat dari faktor kepadatan penduduk yang tinggi serta kenaikan harga hunian yang terus meningkat menyebabkan generasi millennial mulai kesulitan untuk memiliki hunian. Hal-hal ini menjadi tantangan tersendiri untuk merancang hunian seperti apa yang dapat disesuaikan bagi generasi millennial

Selain kebutuhan ruang yang berubah akibat perubahan sosial dan budaya generasi millennial, kepadatan penduduk yang tinggi serta harga hunian yang terus meningkat juga menjadi masalah untuk merancang hunian yang sesuai dengan generasi Millennial. Untuk perancangan hunian yang dapat menyesuaikan kebutuhan ruang generasi millennial baik dari segi aktivitas maupun dari segi jumlah penghuni, kepadatan tinggi, serta harga hunian yang terus meningkat, maka hal yang perlu diperhatikan adalah bagiamana tipe unit ( interior maupun antar modul unit), system yang akan digunakan dalam bangunan hunian, serta fasilitas yang dibutuhkan dalam bangunan hunian. Dapat dikatakan bahwa hunian yang dirancang akan bergerak dalam system hunian fleksibel dan bagaimana system fleksibel ini dapat diterapkan dalam suatu bangunan, sehingga hunian yang dirancang dapat memenuhi kebutuhan generasi millennial serta dapat didukung oleh daya beli generasi millennial.

Batasan proyek kali ini mengacu pada kegiatan dasar penghuni seperti kegiatan kerja, istirakhat, makan, serta kebutuhan kamar mandi sehingga menghasilkan luasan minimal bagi unit yang dapat diisi oleh 1 penghuni. Dari segi jumlah user, terdapat antara 1-4 orang yang akan disesuaikan dengan kemungkinan ekspansi mdul unit berdasarkan katalog yang dirancang yang sesuai dengan kebutuhan ruang penghuni.

\section{KAJIAN LITERATUR}

\section{Generasi Millennial Dalam Berhuni}

Generasi milenial dikenal dengan generasi yang masing-masing individunya memiliki keinginan dan kebutuhan yang berbeda-beda dalam hidupnya. Selain itu generasi ini cenderung memilih untuk memperpanjang masa edukasi dan memilih untuk mengejar karirnya terlebih dahulu sebelum memutuskan untuk menikah(GoldmanSach:2019). Namun hal untuk menikah dan memiliki anak masih menjadi hal relatif sehingga meskipun memiliki kecenderungan untuk menunda pernikahan dan anak, ada saja beberapa orang generasi millennial yang tidak sesuai dengan kriteria diatas. Selain itu ada juga kebiasaan generasi milenial yang saat ini lebih memilih untuk bekerja secara remotely dan banyak juga yang mulai bekerja dari hunian(KPMG:2017) Kebutuhan hunian generasi millennial saat ini lebih diarahkan kepada pengurangan besaran hunian bagi generasi millennial yang baru sanggup memiliki hunian, dengan kecenderuang single household mendominasi hunian (Heckman 2017).

Berdasarkan Neufert Architect Data, dalam hunian terdapat beberapa kegiatan yang dibedakan menjadi beberapa ruang yang akan digunakan bagaimana kebutuhan hunian generasi milenial saat ini. Menurut Neufert Architect Data ruangan hunian terbagi sebagai berikut, Dapur digunakan sebagai tempat untuk memasak, menyiapan makan, dan dapat juga digunakan sebagai ruang makan Living Area terbagi menjadi 3 bagian yaitu berupa kamar yang digunakan untuk beristirahat, ruang tengah, maupun ruang makan yang digunakan untuk 
bersosalisasi dan berkomunikasi, Kamar Mandi/ Ruang Cuci Digunakan untuk membersihakn diri dan mencuci pakaian, dan Storage.

Dari keempat ruang ini maka dilakukan survey quisioner terhadap 100 responden yang terdiri dari generasi milenial berusia 20-30 tahun yang berdomisili di Jabodetabek dengan mayoritas belum memiliki hunian pribadi.

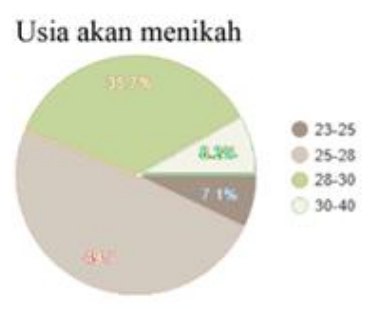

Menunda untuk memiliki anak
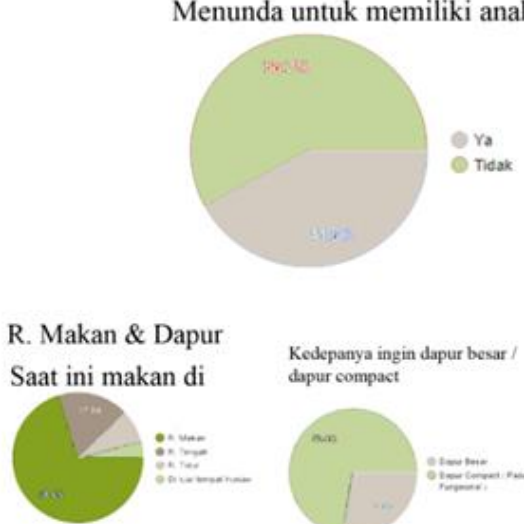

Masak / Order Online

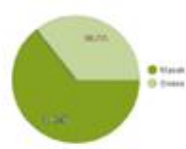

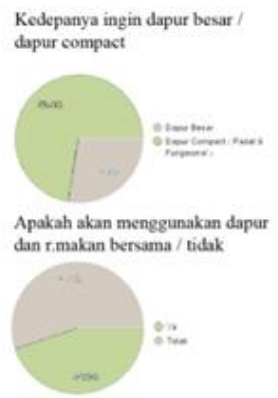

Living Room

Ruang untuk refreshing / hobi

R. Kamar

R. Tengah

Ruang untuk bekerja / tugas

R. Kamar

R. Tengah

R. Kerja

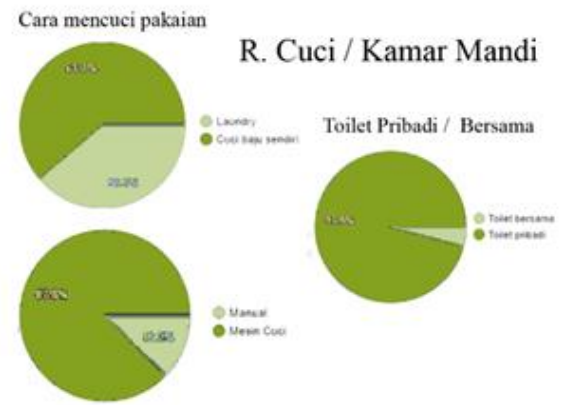

Gambar 1. Grafik Kuisioner

Sumber : Penulis, 2019

Berdasarkan data yang ada dari hasil quisioner dilihat bahwa angka usia pernikahan cenderung bervarian dengan usia 25-30 tahun menjadi usia untuk menikah. Selain itu ada sebagian generasi milenial yang menunda memiliki anak, dan ada juga yang tidak menunda untuk memiliki anak. Untuk ruangan di dalam hunian preferensi generasi milenial cenderung memiliki beberapa kebutuhan yang berbeda 1 sama lain. Namun untuk kamar mandi, generasi milenial lebih memharapkan untuk memiliki kamar mandi pribadi. Selain dari sisi kebutuhan ruang generasi milenial juga membutuhkan ruang bersama dan sarana olahraga.

Dari data quisioner yang ada, hal ini memberikan pernyataan yang sama dengan apa yang ada di literatur. Kebutuhan hunian generasi millennial cenderung fleksibel mengikuti kebutuhan masing-masing individu. Hal ini perlu dikaji mengingat hunian vertikal saat ini kaku dan tidak dapat mengalami perubahan, sehingga diharapkan tercipta hunian fleksibel yang sekiranya dapat menampung kebutuhan generasi milenial, dimana huniannya didasarkan pada apa kebutuhan masing-masing individu, serta jumlah penghuni yang akan menghuni, dengan kemungkinan / memberikan kemungkinan untuk mengembangkan hunian secara fleksible untuk memenuhi kebutuhan pada waktu yang akan datang seperti penambahan anggota penghuni, dll. dengan anggota penghuni sendiri kemungkinan akan diuji untuk menampung 1 orang, 2 orang pasangan, 2 orang pasangan dengan 1 anak, dan 2 pasangan dengan 2 anak. 


\section{Flexible Architecture}

Dalam flexible architecture, sebenarnya hal ini digunakan untuk menambah waktu guna bagi suatu bangunan sehingga mudah untuk digunakan untuk memodifikasi dan untuk merespon kebutuhan sesuai waktu yang berlaku. Pengunaan konsep flexibility ini dapat dilihat dari karakteristiknya yaitu untuk jangka pendek melihat perubahan kebutuhan selama masa operasional sehingga tercipta ruang yang efektif dan Untuk jangka panjang, berkaitan dengan faktor eksternal yang sekiranya akan mempengaruhi suatu bangunan.

Terdapat 4 klasifikasi dan strategi dalam flexibility architecture antara lain :
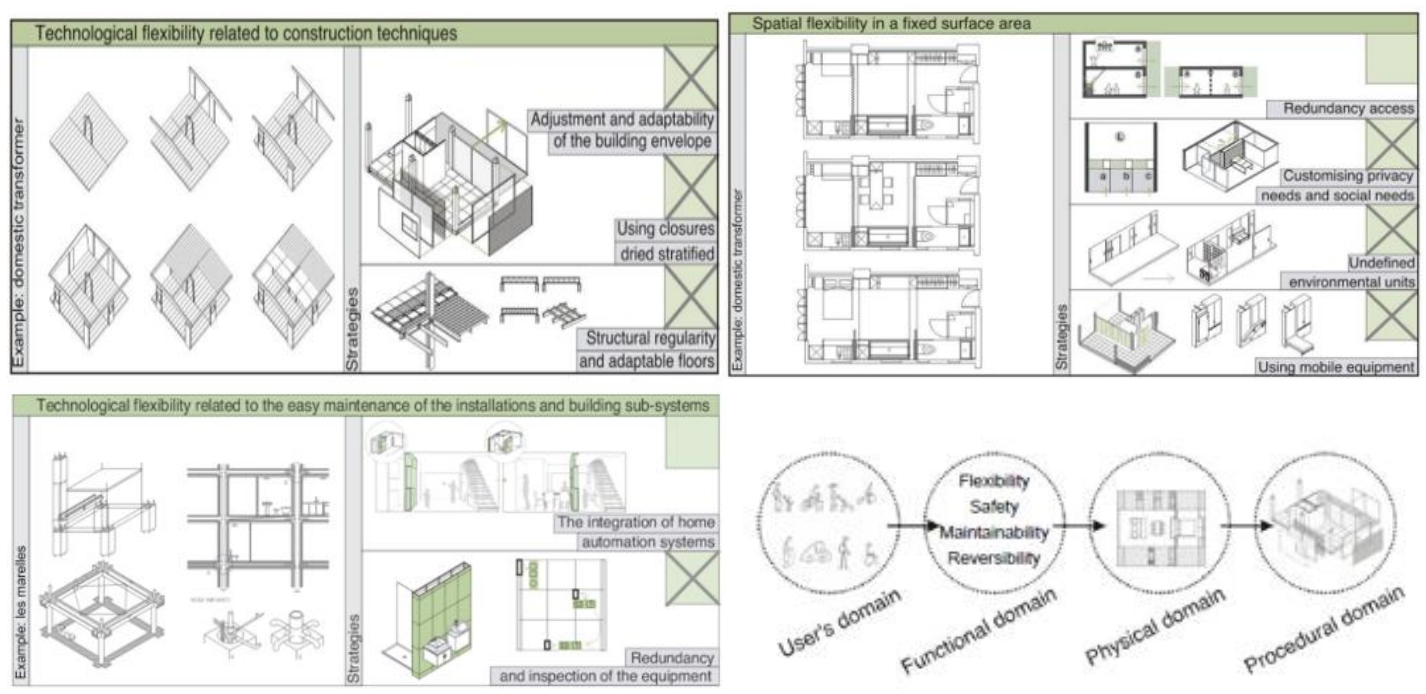

Gambar 2. Flexible Architecture

Sumber : Cellucci, 2015

Spatial Flexibility in a Fixed Surface Area Flexibilitas tipe ini dilakukan dalam satu space ruang yang dimodifikasi menjadi beberapa ruang. Seperti pembedaan ruang privasi, penggunaan interior yang mobile, serta ruangan yang dapat berubah-rubah fungsi dalam ruangan

Evolutionary Spatial Flexibility Flexibilitas tipe ini menggunakan bebererapa cara seperti menambah ruang / permukaan pada struktur yang sudah ada terlebih dahuilu, dapat menggunakan prefabrikasi,dll

Technological Flexibility Related to Construction Techniques Fleksibilitas tipe ini menggunakan teknologi struktur serta penutup bangunan untuk mengembangkan atau mengekspansi ruangan sehingga dapat disesuaikan dengan kebutuhan. Dilakukan dengan cara prefabrikasi maupun semi prefabrikasi untuk memudahkan memodifikasi ruang yang ada

Technological Flexibility Related to Easy Maintenance of the Instalation and Building SubSystem Flexibilitas tipe ini mengedepankan sistem yang berkaitan dengan sistem otomatis yang ada di rumah sehingga dapat menciptakan fleksibilitas dengan cepat. Selain itu diharapkan agar utilitas dapat disesuaikan dengan fleksibilitas yang diinginkan sesuai dengan kebutuhan pengguna.

Dengan demikian untuk menerapkan konsep flexibility dalam hunian dapat dilihat dari beberapa hal yang harus diperhatikan seperti : Memperhatikan kegiatan pengguna dimulai dari fungsi hingga kebutuhan psikologis dengan variasi yang tercipta sepanjang waktu, lalu Design yang ada harus dapat menerjemahkan prnsip-prinsip yang dibutuhkan seperti, fleksibilitas, mantainability, dan reversibility, kemudian fisik domain berhubungan dengan pemilihan spatial dan teknologi yang dapat mengakomodasi domain fungsional, dan proses domain procedural dilakukan untuk menyesuaikan beberapa perubahan yang terjadi pada kebutuhan dan user bangunan yang berubah-ubah dengan juga memperhatikan sistem konstruksi yang efisien dan menggunakan material lokal sebisa mungkin (Celluci:2015) 


\section{METODE}

Metode perancangan yang akan digunakan dalam proyek ini adalah metode "Flexible Architecture ". Dengan meminjam pendekatan pendesainan Flexible Architecture diharapkan hunian yang tercipta akan menunjang kebutuhan generasi milenial yang memiliki kebutuhan yang flexible. Perancangan akan dimulai dengan menentukan variasi user yang akan berhuni disesuaikan dengan program kegiatan dan kebutuhan ruang masing-masing variasi user sehinga menciptakan beberapa modul variasi yang dapat berubah-ubah dan akan disusun menjadi suatu bangunan

Perlu menjadi perhatian yang akan menjadi pertimbangan untuk mendesain dengan pendekatan ini ialah dengan melihat / memperdalam studi dari studi literatur, studi kasus, dan lain-lain terutama dalam flexible architecture hal yang menjadi tantangan terbesar adalah dari faktor struktur dan mekanikal elektikal plumbing yang menjadi tulang belakang sebuah bangunan

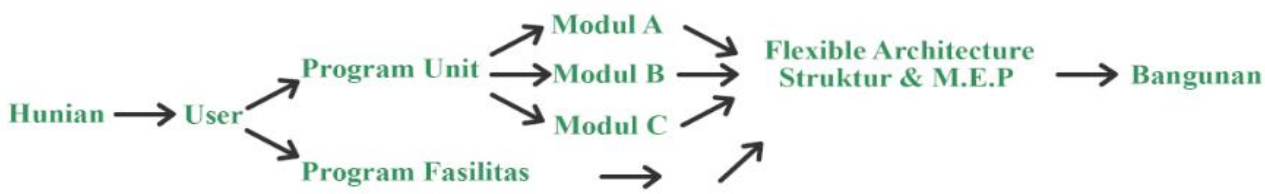

Gambar 3. Skema Penyusunan Unit Sumber : Penulis, 2019

Penentuan User Unit : User unit dilihat dari studi literatur, studi dari internet dan pengamatan langsung (Metode Partisipatoris :Wawancara, Observasi, Angket)mengenai bagaimana kehidupan generasi milenial dalam berhuni sesuai dengan karakteristik milenial.

Program Ruang Unit : Program hunian dan penunjang serta user dari hunian flexible untuk milenial, dilakukan pengamatan lebih lanjut melalui literatur, studi dari internet dan studi ergonomic terhadap kebutuhan ruang penghuni yang terdiri dari kegiatan istirahat, makan dan memasak, berkarya, dan sanitasi. Selain itu dilakukan juga teknik pengamatan langsung (Metode Partisipatoris :Wawancara, Observasi, Angket) terhadap beberapa hunian vertikal yang ada di Jabodetabek.

Program Ruang Penunjang : Program ruang penunjang ditinjau dengan Teknik pengamatan langsung (Metode Partisipatoris :Wawancara, Observasi, Angket) kepada beberapa Hunian vertikal yang ada di Jabodetabek serta literatur dan studi internet yang disesuaikan dengan kebutuhan generasi milenial

Penentuan Lokasi : Penentuan lokasi tapak dipilih melalui studi literatur disertai dengan teknik pengamatan langsung (Metode Partisipatoris :Wawancara, Observasi, Angket) mengenai tempat yang sesuai dengan kepadatan tinggi serta banyak generasi millennial. Selain itu dipertimbangan juga kebutuhan proximity tapak, seperti akses, fasilitas penunjang hunian, dll.

\section{DISKUSI DAN HASIL}

Untuk merancang hunian bagi generasi millennial maka dilakukan pendekatan fleksibilitas dalam ruang maupun antar ruang. Pada perancangan ini ditentukanlah tapak dengan kriteria sebagai berikut: 


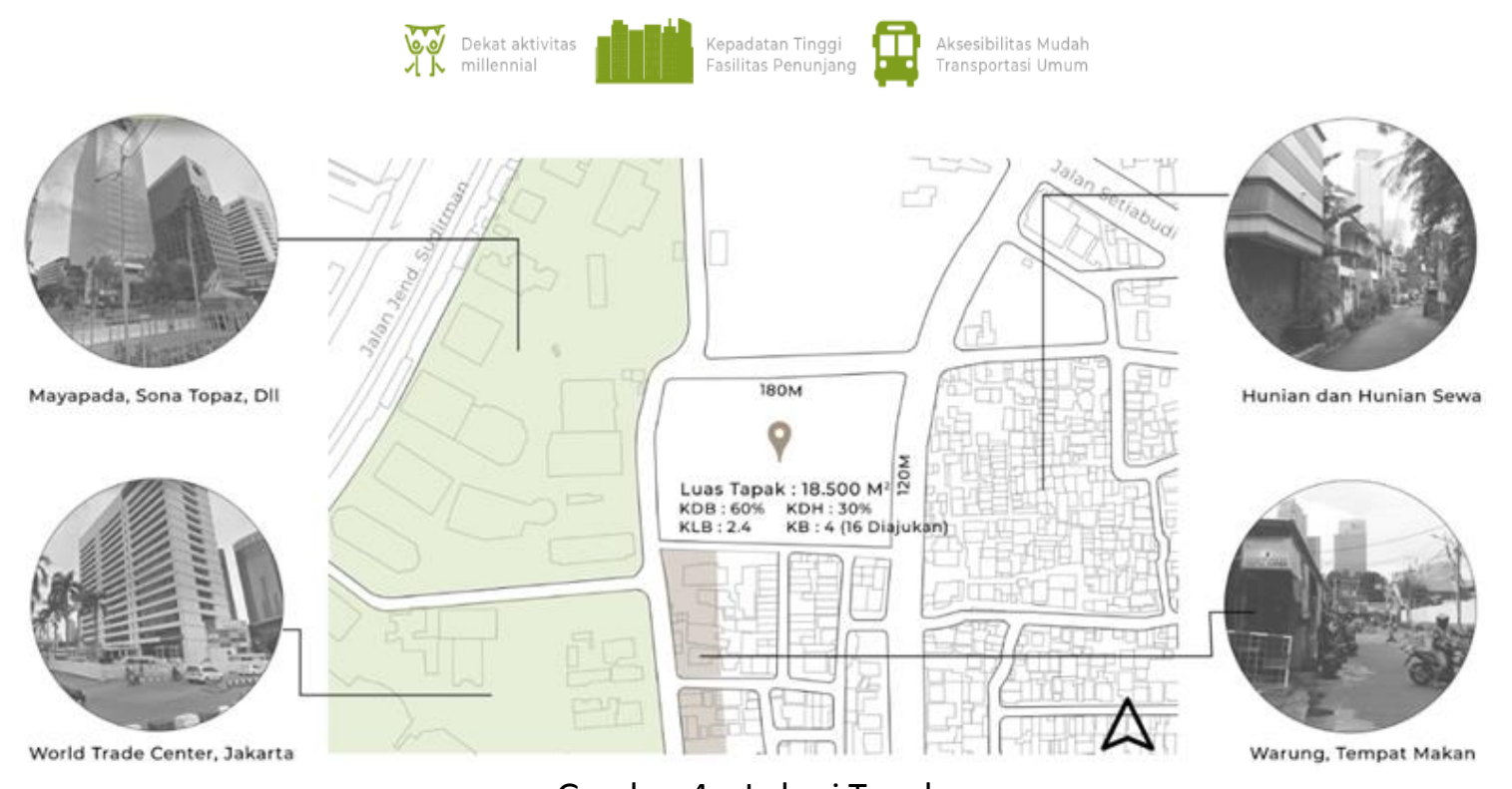

Gambar 4 . Lokasi Tapak

Sumber : Penulis, 2019
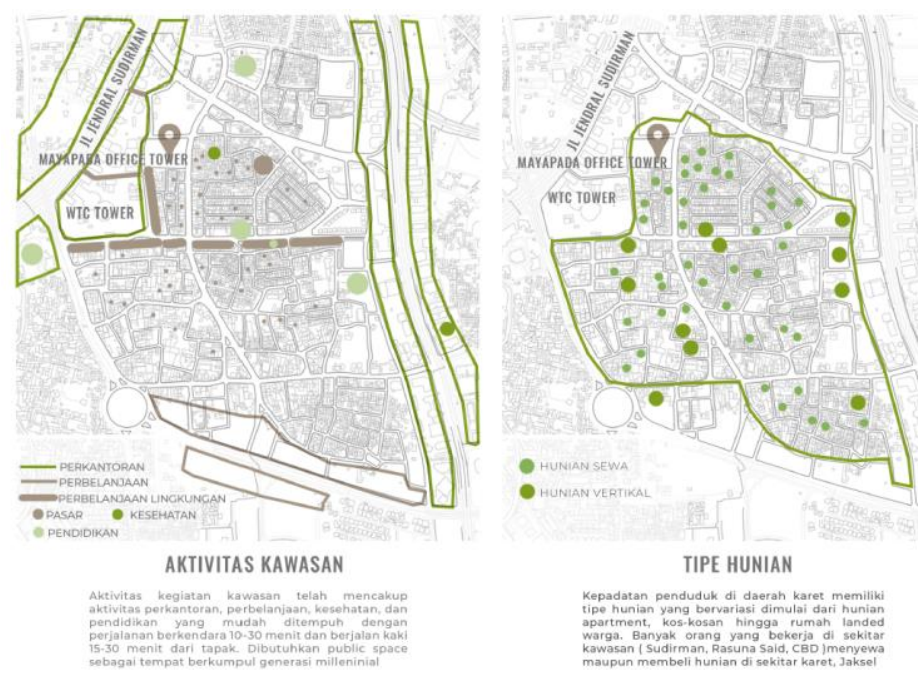

Gambar 5 . Analisa Tapak

Sumber : Penulis, 2019

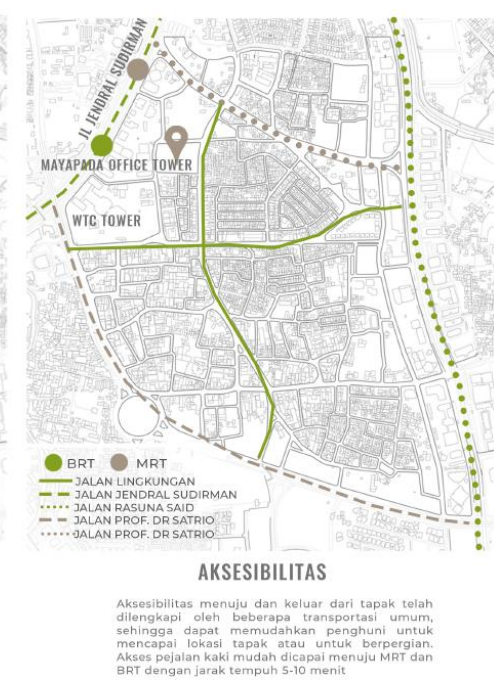

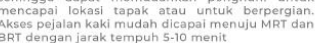

Lokasi tapak terletak di daerah Karet, Setiabudi memiliki potensi untuk dijadikan sebagai lokasi hunian bagi generasi millennial, dilihat dari aksesibilitas yang dilewati oleh jalur arteri jalan Jendral Sudirman, serta dilalui oleh transportasi publik seperti Transjakarta dan MRT. Selain itu pusat perbelanjaan, perkantoran dan pendidikan juga mencakup jarak 30 menit dengan berkendara. Saat ini lokasi perancangan banyak dikelilingi oleh pemukiman serta area hunian sewa (Kos-kosan). Lokasi sekitar tapak masih membutuhkan ruang terbuka untuk berkumpul dan mengakomodasi kepadatan hunian yang tinggi. sehingga diharapkan agar rancangan dapat berkontribusi pada lingkungan sekitar. 
Program utama perancangan diisi oleh beberapa elemen yang dapat menunjang kegiatan hunian Untuk ukuran unit disesuaikan dengan studi kasus dan studi ergonomic.
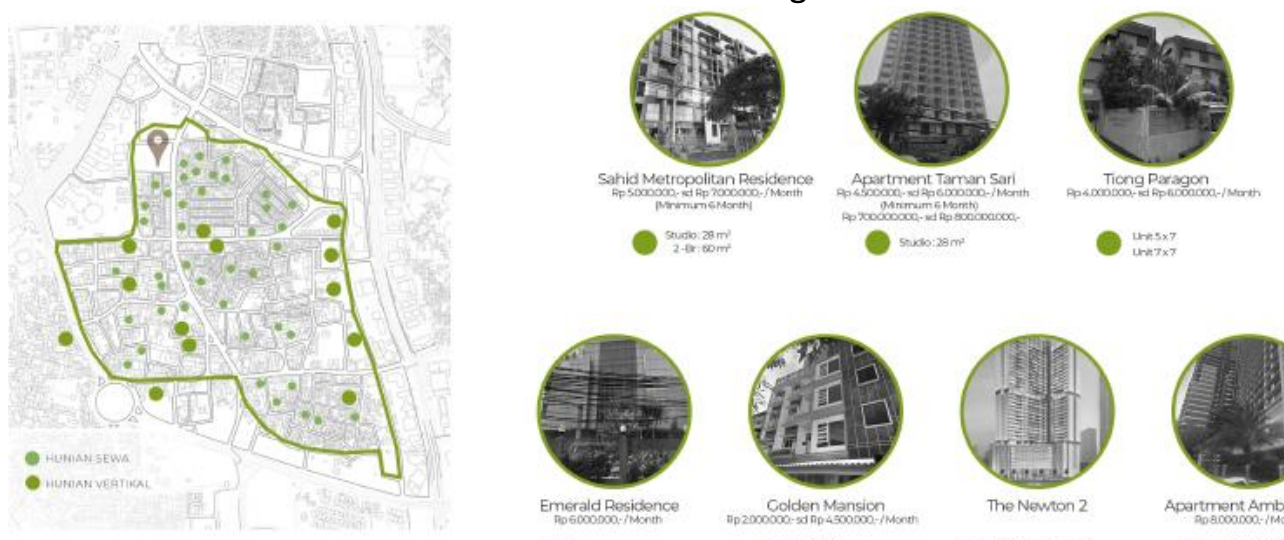

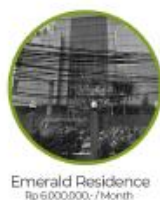

sndo: $24 m$

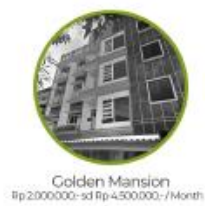

Une $3 \times 5$

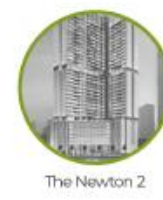

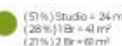

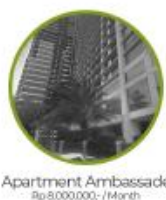

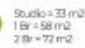

Gambar 6. Studi Pasar

Sumber : Penulis, 2019

Bila dilihat dari studi kasus lapangan terlihat bahwa target pasar yang ada berkisar antara millennial kelas menengah hingga millennial kelas atas dengan unit Tipe Studio \& 1-BR mendominasi pasar.
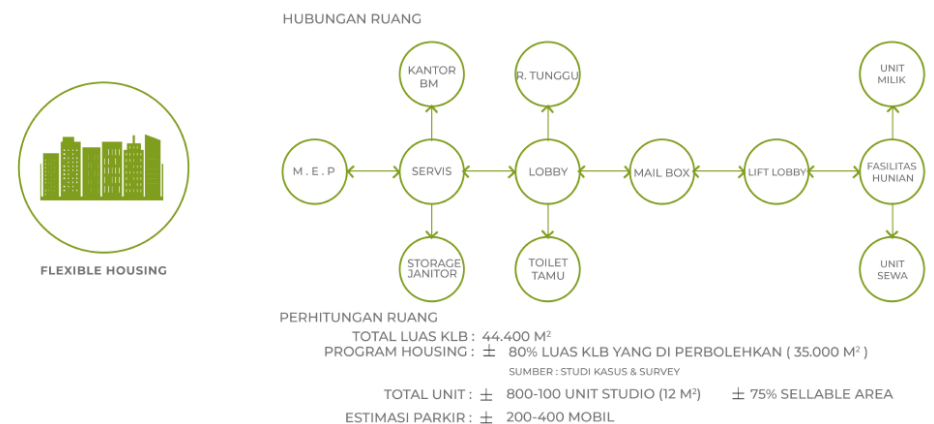

Gambar 7. Program Hunian

Sumber : Penulis, 2019

Dari studi yang ada maka program rancangan hunian akan dibagi menjadi 2 area yaitu luas area yang dapat dijual ( unit ) dan luas area yang tidak dapat dijual fasilitas penghuni, fasilitas penunjang, dll. Dari program hunian $\pm 37.900 \mathrm{~m}^{2}$ (90\% dari total perancangan ) akan digunakan $80 \%$ dari luas untuk program hunian yaitu sebesar $\pm 30.320 \mathrm{~m}^{2}$ untuk unit dan area yang tidak dapat dijual sebesar $\pm 7.600 \mathrm{~m}^{2}(20 \%)$.

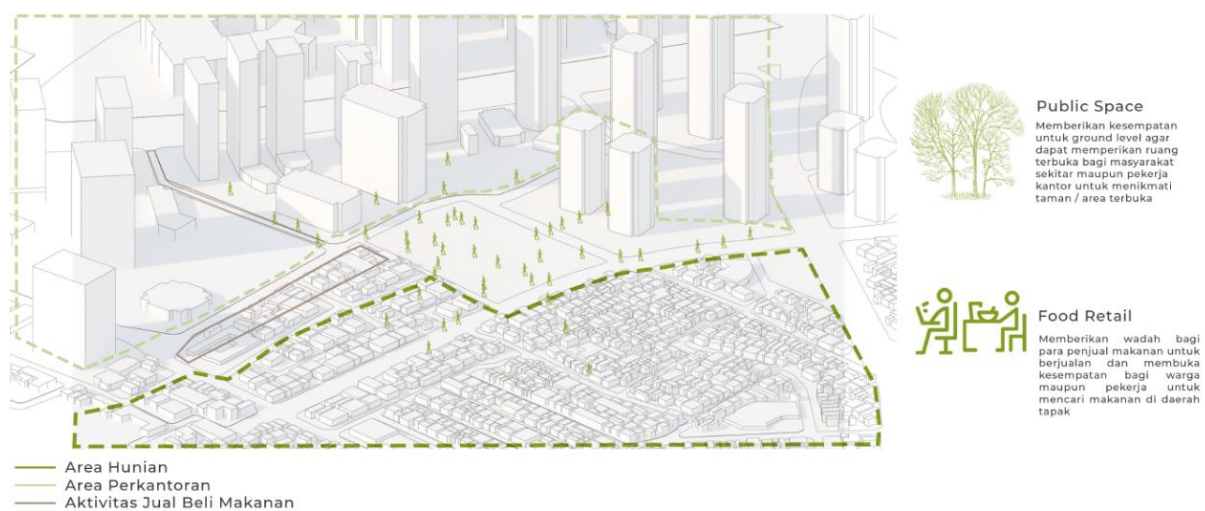

Gambar 8: Program Penunjang

Sumber : Penulis, 2019 
Program penunjang berfungsi sebagai kontribusi terhadap lingkungan sekitar dengan menyediakan ruang terbuka serta area tempat makan yang dapat menghidupkan daerah sekitar. Area terbuka ini dapat juga digunakan oleh penghuni untuk kegiatan masing-masing
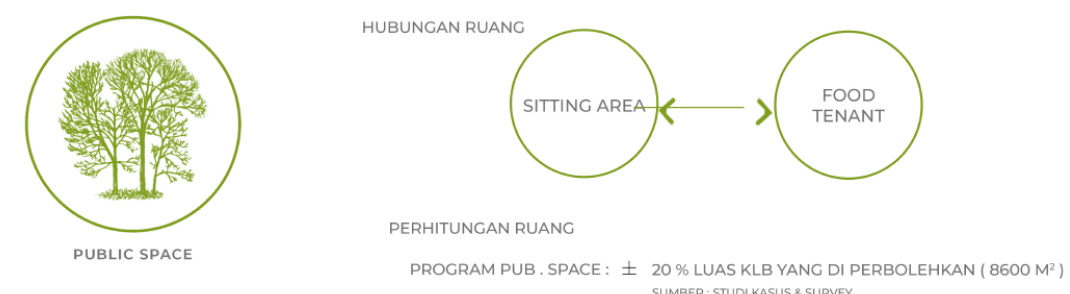

Gambar 9.: Program Penunjang

Sumber : Penulis, 2019

Perhitungan program penunjang didapatkan dari studi kasus terhadap beberapa hunian vertikal yang terdapat di daerah Jakarta dan sekitarnya. Dari hasil studi, 10-20\% program bangunan diisi program penunjang seperti mixed use, menjadi tempat makan, dll. Dalam hal ini luasan yang digunakan adalah $10 \%$ dari total luas perancangan dengan program retail, food and beverage area dan taman terbuka publik.

\section{Konsep Perancangan - Flexible Architecture}

HOUSING UNIT
SYSTEM \& DESIGN
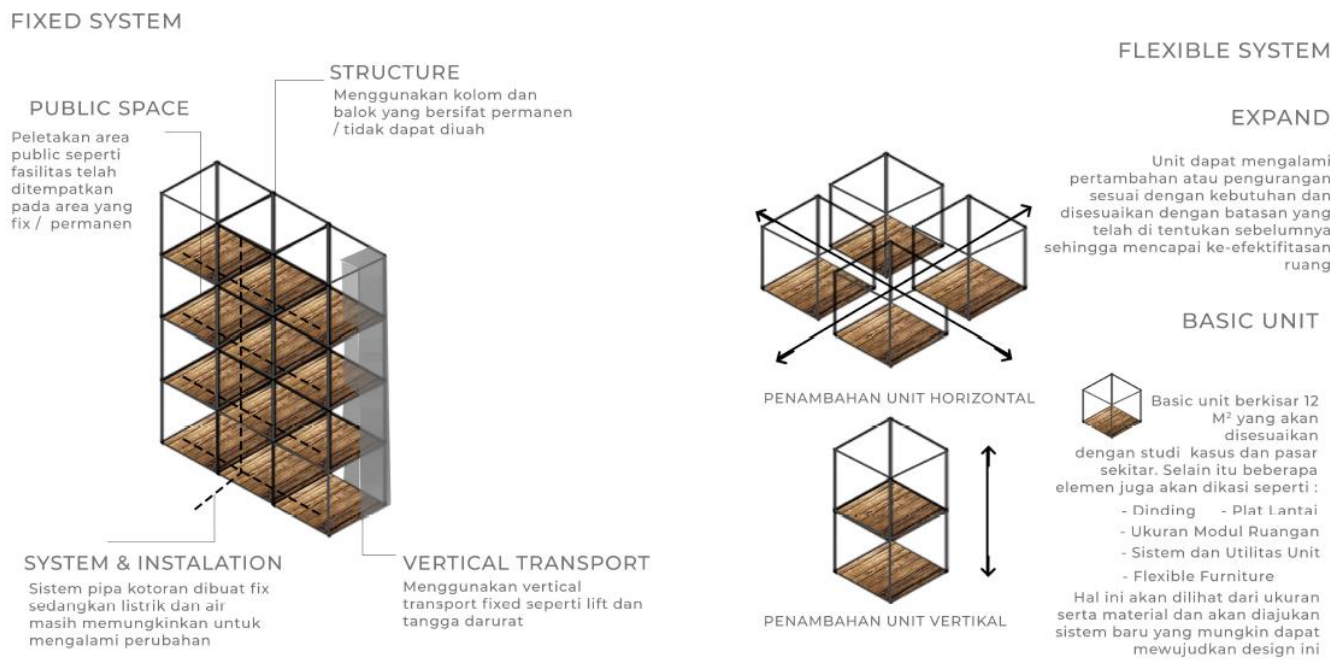

Gambar 10. Sistem Hunian Fleksibel

Sumber : Penulis, 2019

Untuk menerapkan prinsip fleksibilitas dalam bangunan hunian fleksibel ini, pada awalnya ditentukan terlebih dahulu sistem apa saja yang akan dapat diubah secara fleksibel dan sistem apa saja yang tidak dapat diubah secara fleksibel.

Pembagian fixed system atau sistem yang tidak dapat diubah-ubah terdiri atas peletakan struktur bangunan yang akan memangku beban bangunan, sistem transportasi vertikal, baik lift maupun tangga darurat, penggunaan sistem instalasi mekanikal, elektrikal, dan plumbing, serta peletakan-peletakan ruang bersama. Hal ini menjadi batasan fleksibilitas yang dapat diraih oleh bangunan hunian fleksibel ini, sehingga bangunan hunian fleksibel ini dapat berfungsi dengan baik. 
Sistem fleksibel atau flexible system digunakan antar modul unit yang dapat menghubungkan beberapa modul unit secara horizontal dan vertikal sesuai dengan katalog yang ada sehingga bermain dengan perubahan dinding, plat lantai (ditempat tertentu), furniture fleksible, dan elektrikal untuk posisi saklar dan stop kontak.

\section{Massing \& Design Scheme}
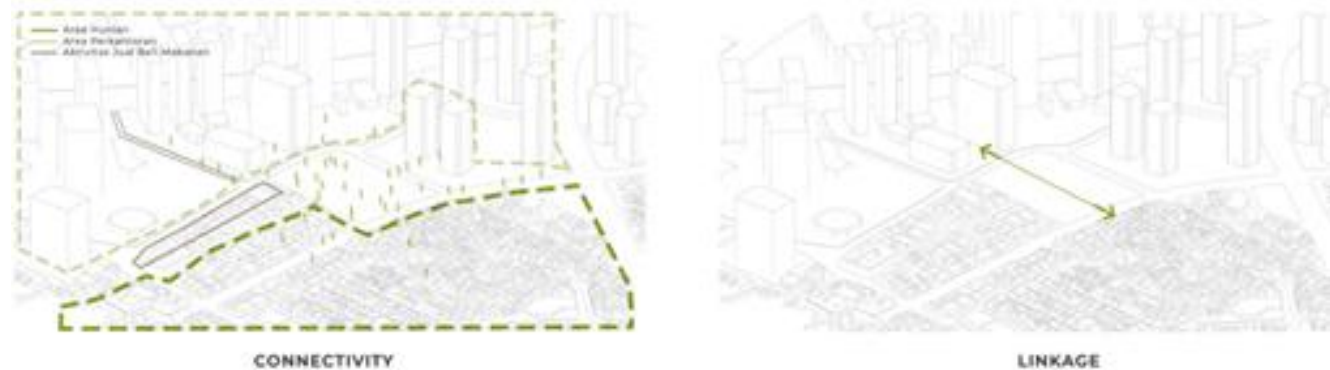

UNKACE

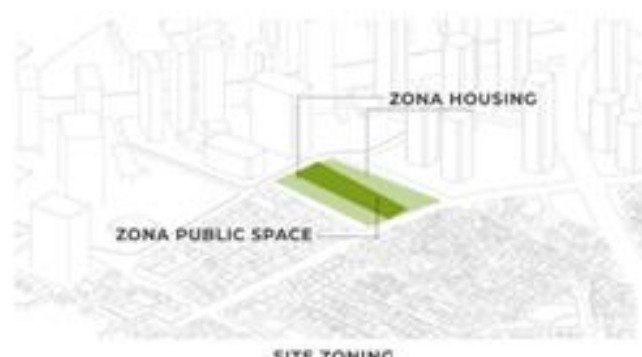

SITE ZONINC

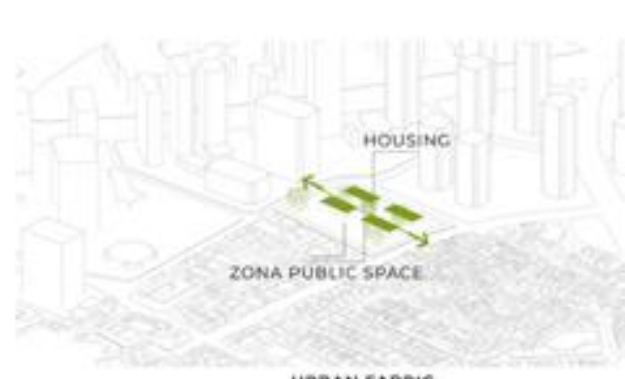

URBAN FABRIC
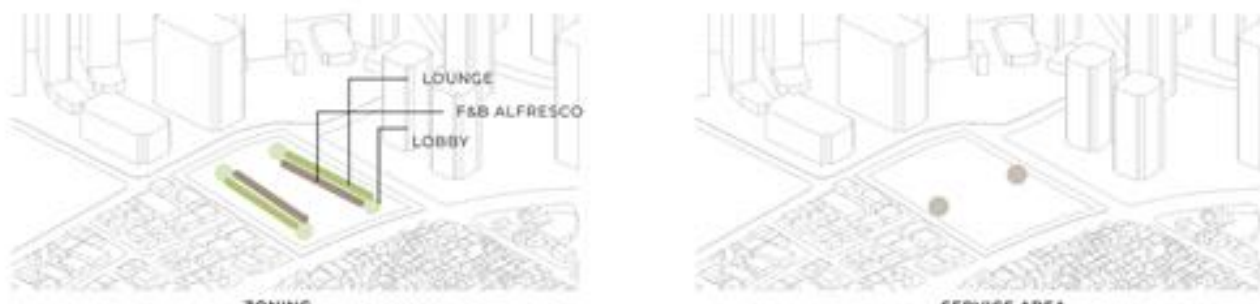

ZONINC

SERvice aGeA

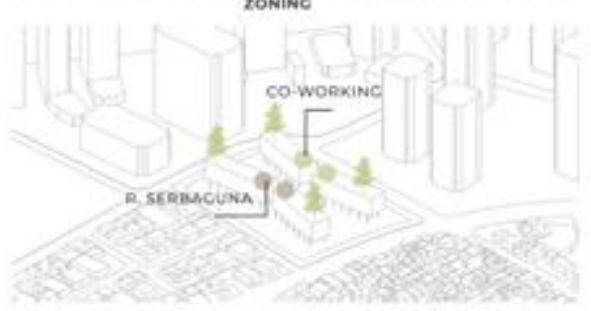

faciuties :

EACILITIES 2
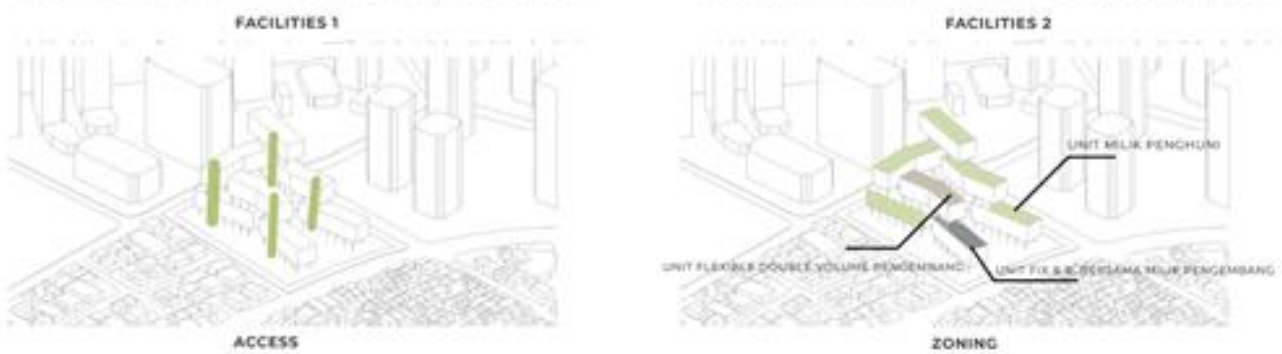

Gambar 11. Massing

Sumber : Penulis, 2019

Perancangan hunian fleksibel dimulai dengan menentukan skema proses gubahan massa dan zonasi yang tentukan sesuai dengan analisa tapak. Lokasi tapak terdapat perumahan penduduk, hunian sewa ( kos-kosan ) sekitar serta dikelilingi oleh perkantoran, sehingga banyak masyarakat yang berlalu lalang untuk menuju maupun kembali dari perkantoran. 
Dalam hal ini pembagian massa dimulai dengan melihat bagaimana perpaduan antara daerah privat bagi penghuni hunian fleksibel dengan masyarakat sekitar yang melintas di sekitar tapak. Dari ide atau gagasan ini maka dibentuklah 2 zoning utama dalam tapak yaitu zoning untuk hunian dan zoning untuk ruang publik, dimana ruang publik diapit oleh 2 area hunian yang nantinya akan menjadi area privat bagi penghuni bangunan. Dengan terbentuknya kedua zoning ini, diharapkan agar zona publik ini menjadi menyatu dengan bangunan hunian fleksible namun tetap menjaga privasi dari penghuni hunian.Ruang publik pada lantai dasar diisi dengan berbagai retail dan food \& beverage area yang akan mengakomodasi kegiatan bersantap serta perlengkapan seperti minimarket, apotik, dan laundry pakaian, serta menjadi tempat bagi penghuni maupun penduduk sekitar untuk bersantai dengan bersantap di tengah alfresco

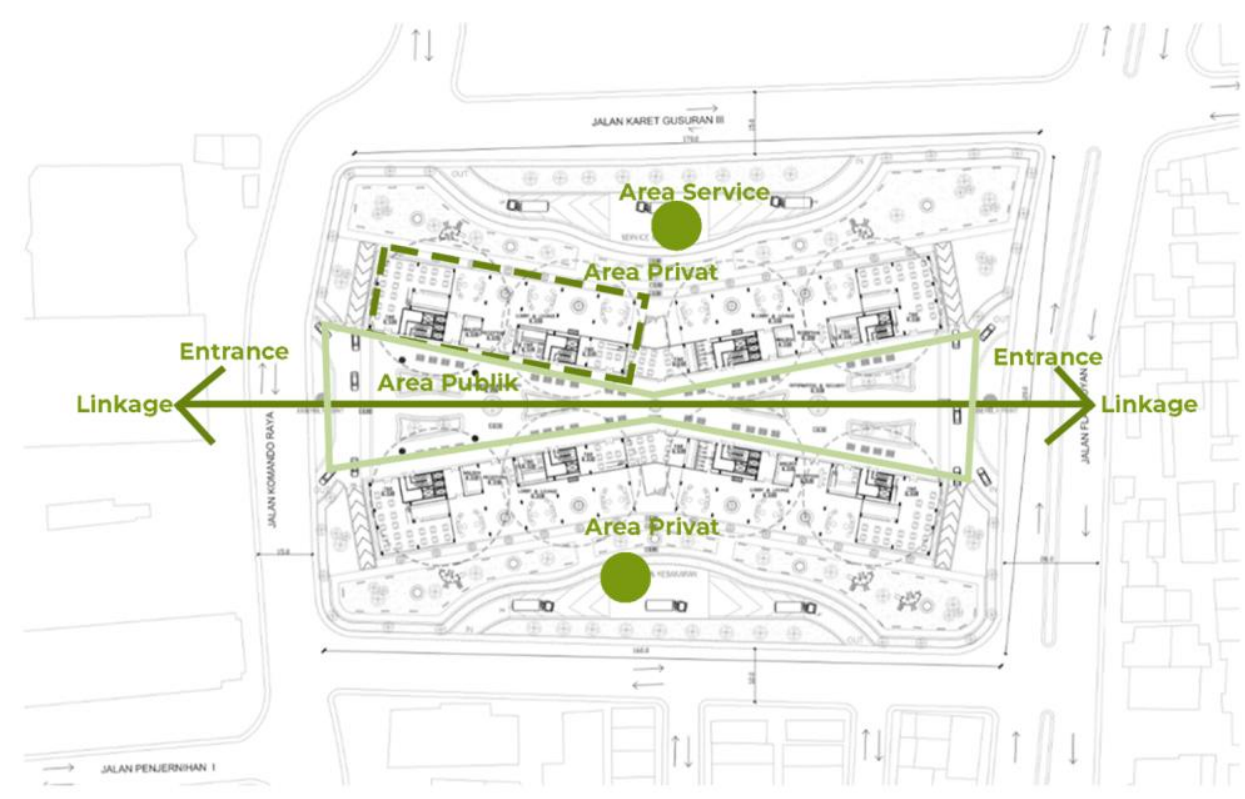

Gambar 12. Site Plan

Sumber : Penulis, 2019

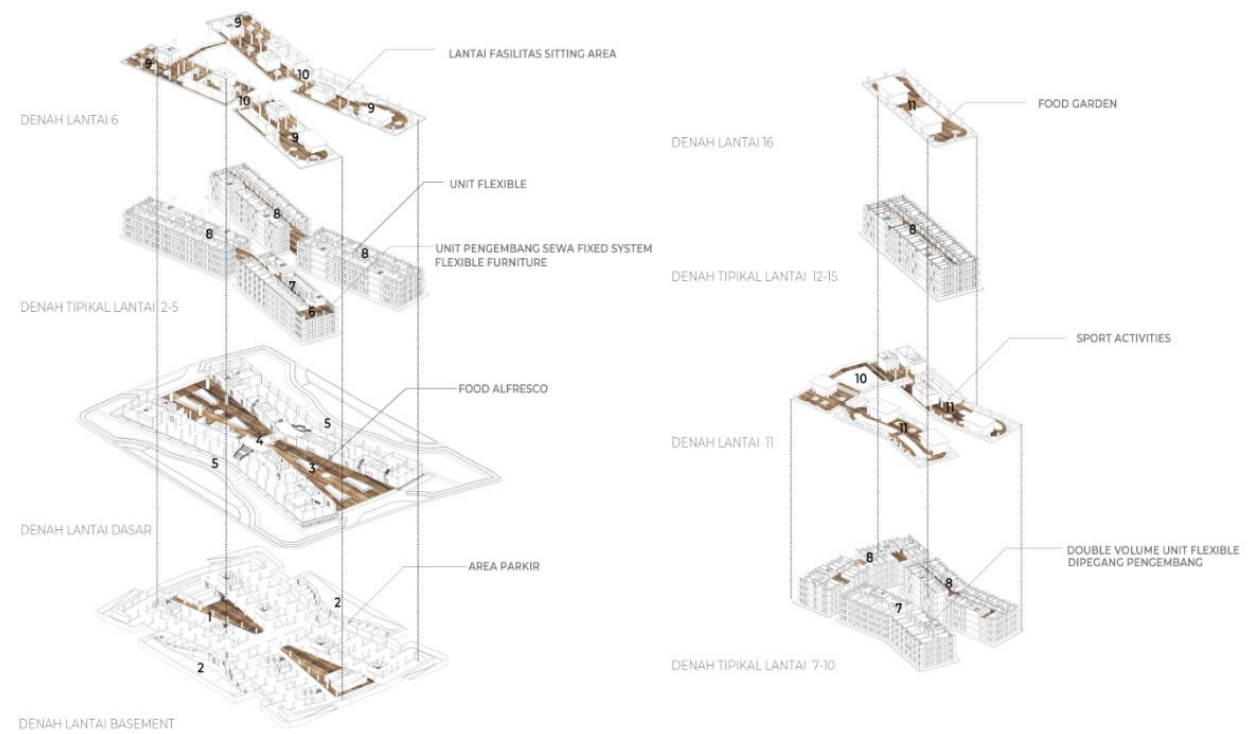

Gambar 13. Axonometri Program Bangunan Sumber : Penulis, 2019 
Bentuk bangunan terbentuk dari massa slab setebal 4 lantai yang ditumpuk dan disusun sehingga membentuk gubahan massa hunian. Hal ini dilakukan agar memberikan tampilan bagi bagi hunian yang selama ini terlihat monoton. Antara tumpukan blok massa yang terdiri dari 4 lantai ini terdapat lantai fasilitas yang digunakan sebagai ruang bersama ( ruang duduk, kerja, $\mathrm{dl})$, ruang olahraga hunian, dan ruang taman tanaman konsumsi. Hal ini untuk meningkatkan komunitas dan sosial yang baik yang akan terbentuk dalam hunian. Pembagian hunian sendiri terdapat hunian sewa permanen, serta sewa double volume yang dikelola pengembang, serta hunian fleksibel sistem jual.

\section{Unit Concept}

HOUSING UNIT

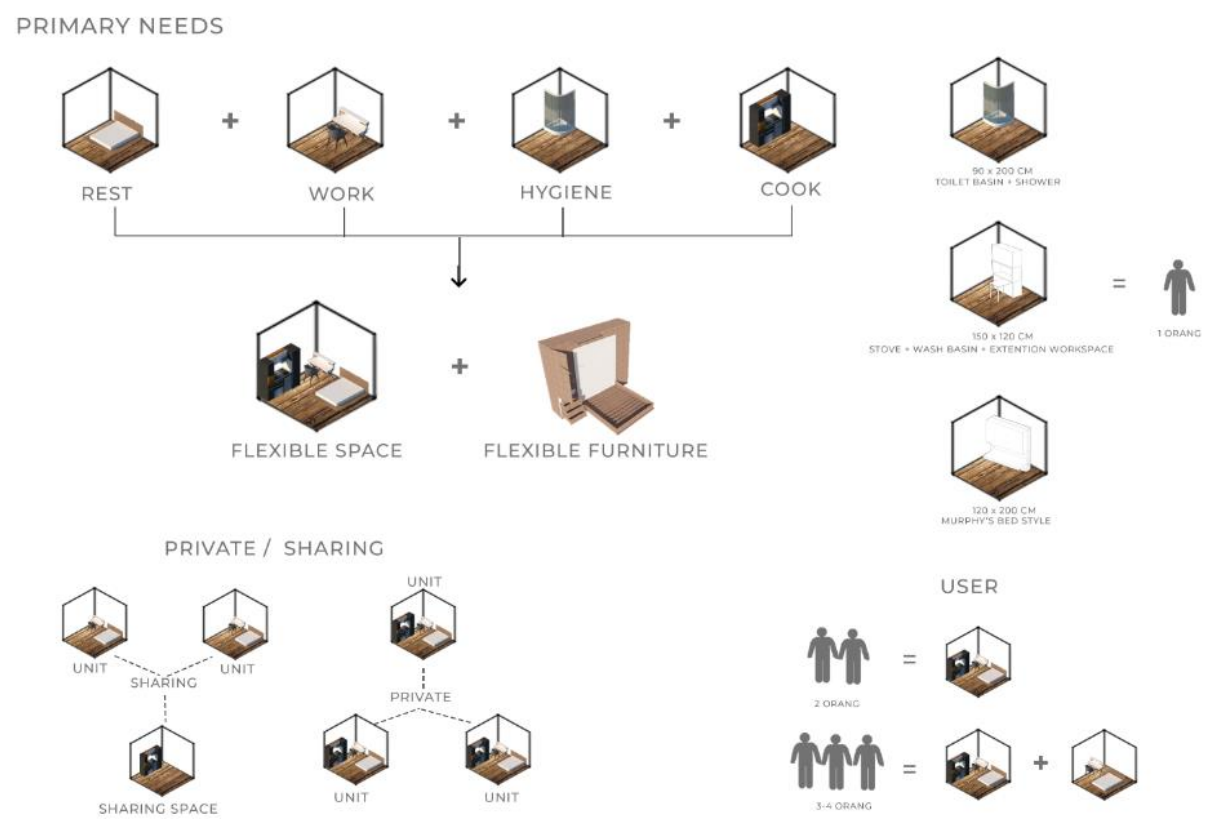

Gambar 14. Axonometri Program Bangunan

Sumber : Penulis, 2019

Unit hunian dibentuk sesuai dengan beberapa kebutuhan generasi millennial sehingga menghadirkan berbagai pilihan. Unit terkecil diawali dari fleksibilitas ruang unit terkecil yang tercipta akibat fleksibilitas dalam 1 modul unit dibantu dengan furniture fleksibel sehingga tercipta unit $2.1 \times 6$ meter untuk 1 penghuni. Setiap pertambahan penghuni dapat digunakan kelipatan modul menjadi 2 modul unit / 3 modul unit sesuai kebutuhan dan daya beli user. Diperlukan perangkat ruang modular sehingga dapat dengan mudah di ubah jika sewaktu2 terjadi perubahan jumlah modul unit. Unit terkecil 1 modul dibantu dengan flexible furniture. Sedangkan modul dengan kelipatan 2 atau 3 modul dapat diisi sesuai dengan kebutuhan penghuni, sehingga yang dijual bagi penghuni merupakan lot kosong yang dapat digunakan dengan toilet prefabrikasi. Hal yang menjadi permanen adalah peletakan MCB, peletakan Pipa harus ditetapkan terlebih dahulu sehingga bila terjadi perubahan terhadap unit sistem instalasi ini sudah siap untuk di gunakan oleh user baru. Untuk fasade penggunaan expanded metal digunakan sebagai pelindung dari matahari serta memberikan privasi view dari luar. Untuk area Servis diletakkan di area basement yang juga terdapat Gudang serta tempat reparasi bagian modular dari unit seperti dinding, fasade, pintu, dll 

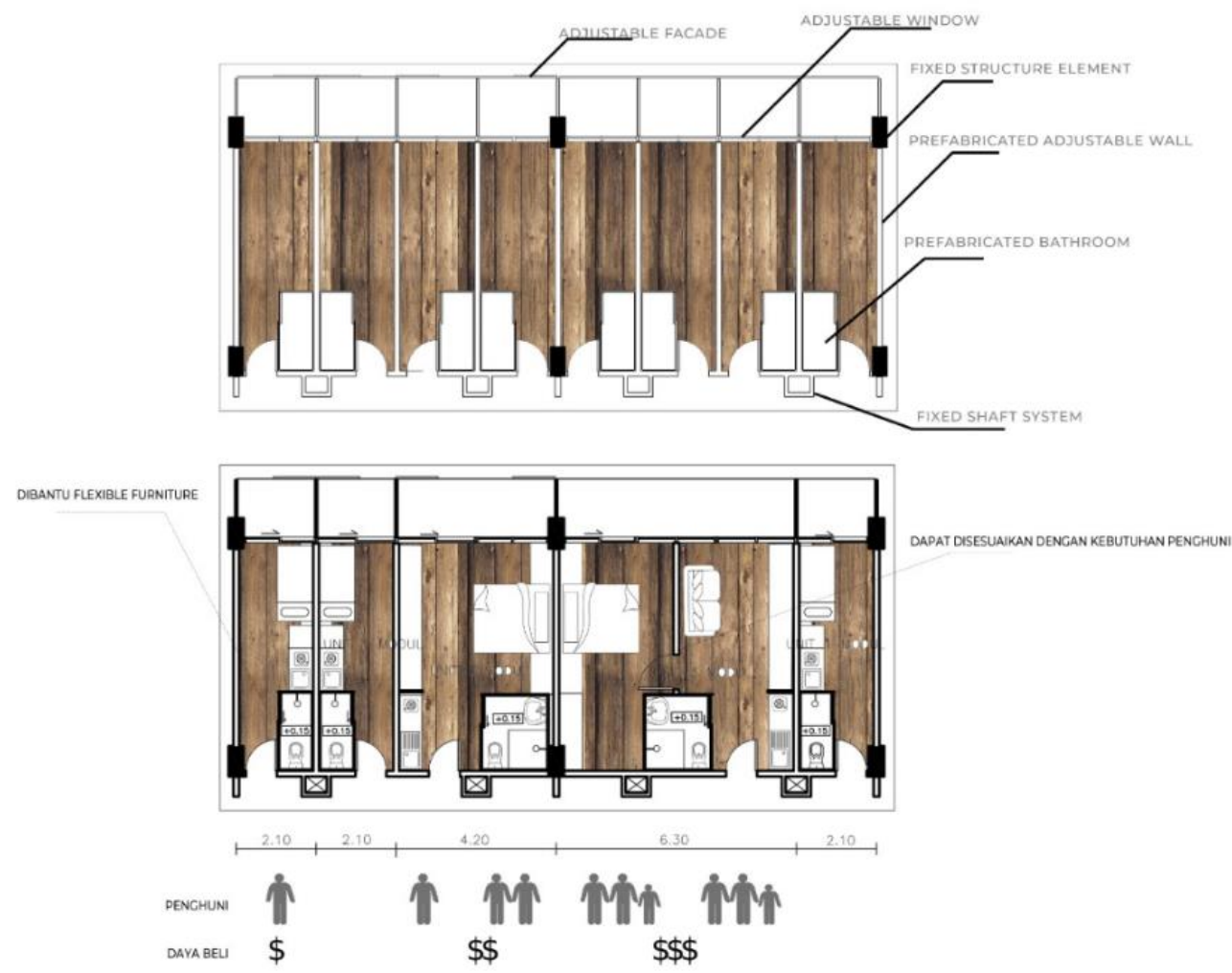

Gambar 15. Skema Unit

Sumber : Penulis, 2019

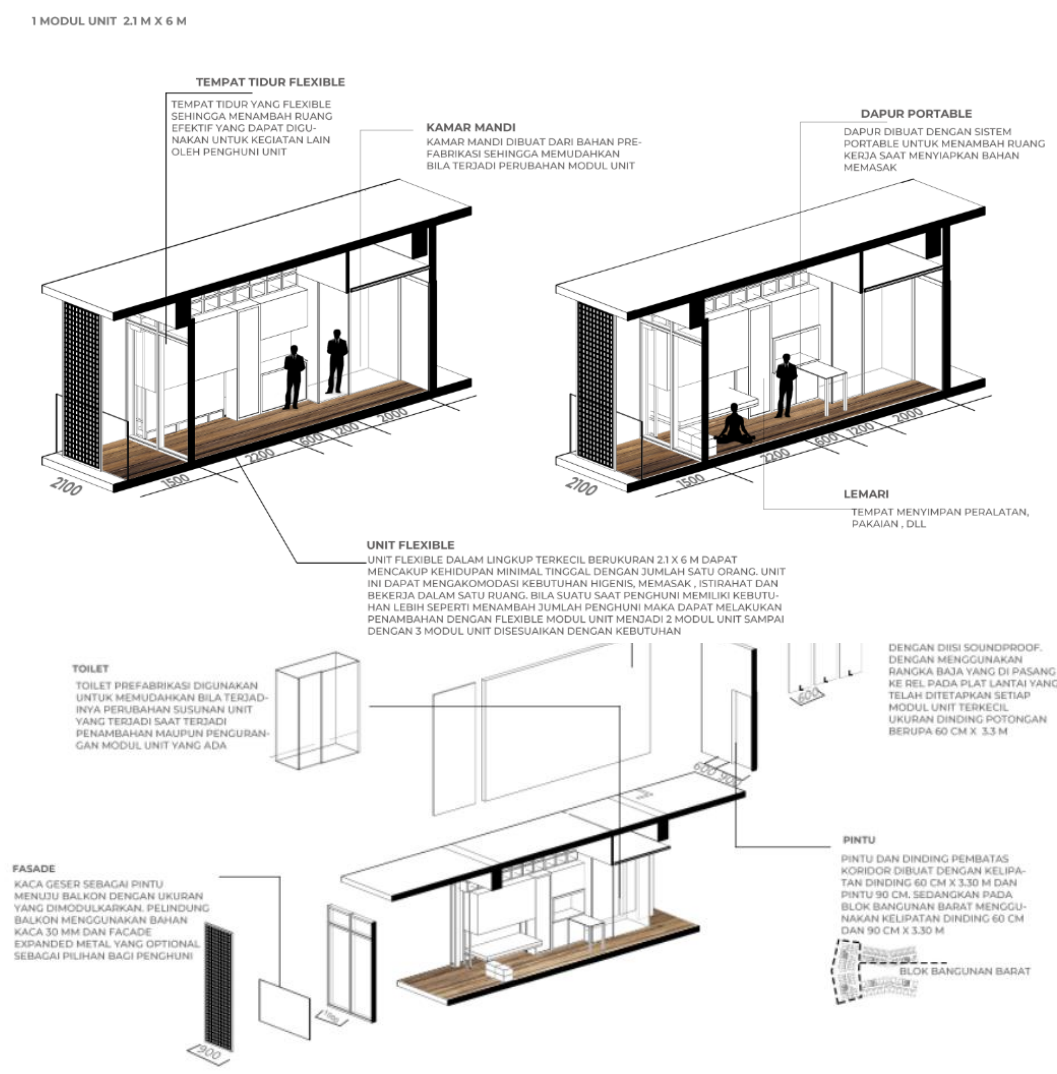

Gambar 16. Detail Unit

Sumber : Penulis, 2019 


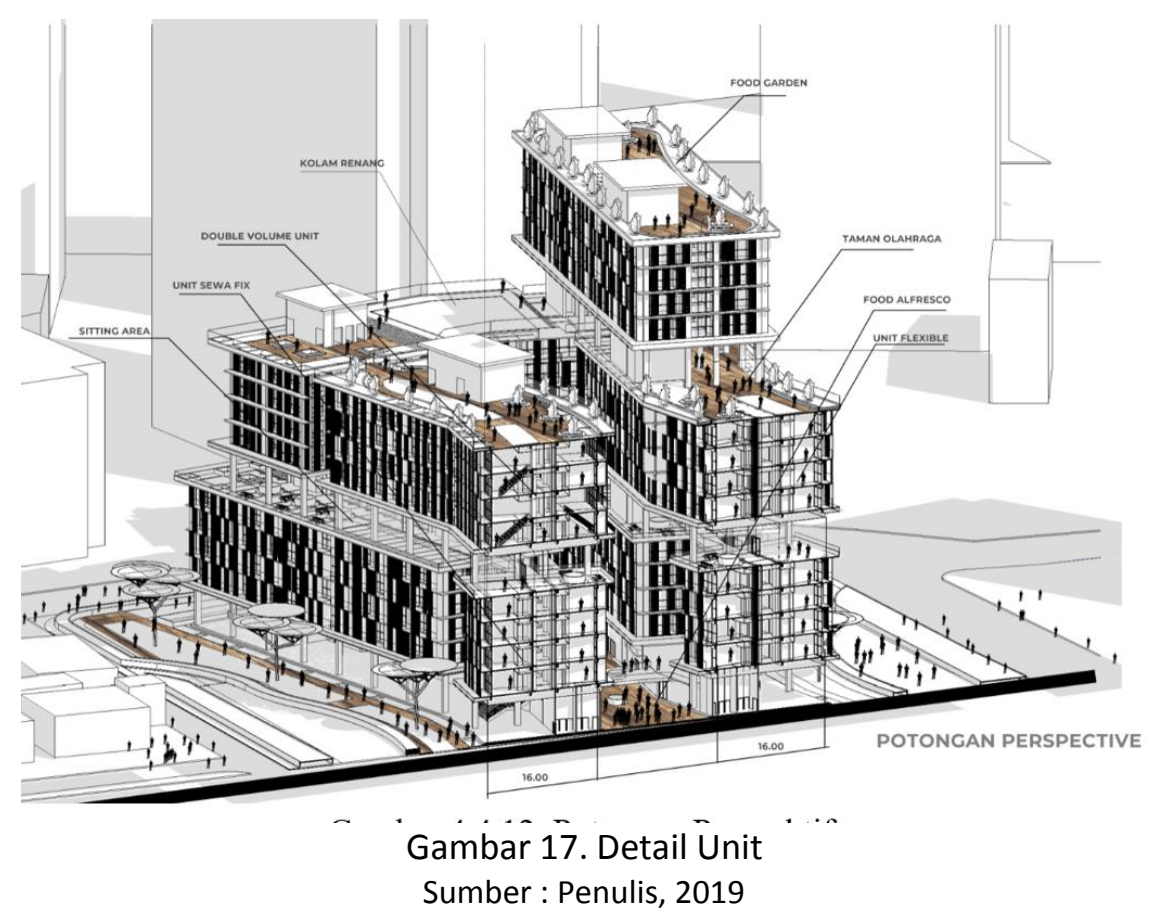

\section{KESIMPULAN DAN SARAN}

Merancang hunian yang dapat mengakomodasi kebutuhan generasi millennial dapat dimulai dari mempelajari bagaimana cara hidup dan bersosialisasi generasi millennial saat ini. Generasi millennial ini membutuhkan sebuah ruang yang fleksibel yang dapat beradaptasi secara waktu ke waktu. Hal ini dikarenakan generasi millennial mempunyai banyak jenis kebutuhan, dan dikenal sebagai generasi yang gaya hidupnya dinamis / selalu berubah. Selain itu hunian yang akan disediakan juga dipengaruhi oleh kepadatan penduduk di Jakarta yang semakin meningkat serta harga properti yang terus meningkat dari waktu ke waktu. Hunian Fleksibel yang di rancang pada perancangan kali ini mengacu kepada pemenuhan kebutuhan ruang bagi generasi millennial yang dapat berubah-ubah baik secara jangka waktu singkat, maupun jangka panjang. Seperti misalnya dalam keseharian maka sebuah ruang dapat bertranformasi dari ruang tidur menjadi ruang kerja, dll. Contoh untuk jangka panjang adalah penambahan anggota penghuni unit. Hunian fleksibel ini bertujuan agar memberikan kemungkinan bagi unit untuk berubah dalam satu modul unit terkecil yang dibantu dengan furnitur fleksibel maupun perubahan antar modul unit seperti penambahan maupun pengurangan modul unit. Tentunya hal ini disesuaikan dengan katalog yang telah disediakan sehingga selain dapat memenuhi kebutuhan generasi millennial juga dapat didukung dengan daya beli yang baik oleh generasi millennial.

Untuk menghasilkan sebuah Hunian Fleksibel tentu ada batasan-batasan sehingga tidak semua bagian dari bangunan dapat berubah-ubah atau fleksibel. Struktur, Utilitas, Fasilitas Bersama, dan Sistem transportasi vertikal merupakan contoh komponen bangunan yang tidak dapat bersifat fleksibel Sedangkan untuk pembatas antar ruang antar modul unit terkecil digunakan material-material prefabrikasi yang telah ditentukan besaran-besarannya. Sehingga dapat memudahkan apabila akan terjadi perubahan. Selain itu untuk fasilitas bersama hunian diletakan secara tersebar sehingga memudahkan para penghuni untuk dapat bersosialisasi dengan penghuni lainnya

Saran bagi pengembangan perancangan ini adalah untuk lebih mendetailkan bagaimana sambungan - sambungan yang kemungkinan akan terbentuk pada saat waktu kedepan dimana perkembangan teknologi akan semakin meningkat. Saran bagi pelaksana di lapangan mengenai arsitektur fleksibel adalah lebih banyaknya industry bangunan prefabrikasi yan dibangun di dekat kota untuk menyiapkan proyek prefabrikasi unit modular sehinggal biaya transportasi dan produksi dapat diminimalisir 


\section{REFERENSI}

Cellucci, C., Sivo, M. D. (2015). The Flexible Housing: Criteria and Strategies for Implementation of the Flexibility. Public Administration doi, 10.17265/19347359/2015.07.011

Doling, J. Ronald,R. (2014) Housing East Asia : Socioeconomic and Demographic Challenges, Basingstoke, England : Palgrave Macmillan

Goldman, S. (2019). Millennials : Coming of Age. Retrieved January 16, 2019 fromGoldmanSach: https://www.goldmansachs.com/insights/archive/millennials/

Heckman,E., Zapel.E. (2018) Floor Plan Manual : Housing $5^{\text {th }}$ Edition ( A Chronical Development In Housing) Basel, Switzerland: Birkhauser

Ipsos. (2017). Ipsos Mori Thinks: Millennials Myths and Realities. Retrieved January 16, 2019 , from Ipsos: https://www.ipsos.com/ipsos-mori/en-uk/millennial-myths-and-realities

KPMG. (2017). Meet The Millennials . Retrieved Januari 16, 2019, from KPMG: https://home.kpmg/content/dam/kpmg/uk/pdf/2017/04/Meet-the-MillennialsSecured.pdf

Reza, S. H. R. Eteghad, A. N. Guardiola, E. U. Flexible Housing : The Role of Spatial Organization in Achieving Functional Efficiency. Public Administration doi, 10.26687/archnetijar.v9i2.422 